\title{
Ganglioside as a Prophylactic Agent in Experimental Tetanus in Mice
}

\author{
By JANE MELLANBY, HELEN MELLANBY, DIANA POPE \\ AND W. E. VAN HEYNINGEN \\ Sir William Dunn School of Pathology, University of Oxford
}

(Accepted for publication I7 June 1968)

\begin{abstract}
SUMMARY
The symptoms of tetanus in mice, resulting from intramuscular injection of either purified tetanus toxin or vegetative bacilli of Clostridium tetani, can be partially prevented if the mice are injected at the same time, or a few hours before or afterwards, with a preparation of mixed gangliosides or with a suspension of ganglioside/cerebroside complex. Injection at the same site as the toxin injection is most effective, although intravenous injection of ganglioside (but not of the complex) also has some action; $0.5 \mathrm{mg}$. of ganglioside when complexed with $1.5 \mathrm{mg}$. cerebroside is as effective in protection as $5 \mathrm{mg}$. ganglioside alone. Protection by complexes containing different proportions of ganglioside reflects their ability to fix tetanus toxin in vitro. It is tentatively suggested that injection of ganglioside/cerebroside complex at a site of injury might be of prophylactic value in human tetanus.
\end{abstract}

\section{INTRODUCTION}

Tetanus toxin combines with nervous tissue (Wassermann \& Takaki, I898), and the receptor substance for the toxin involves gangliosides (van Heyningen, 1959; van Heyningen \& Miller, I96I; van Heyningen \& Mellanby, 1968). It is not known whether the combination of tetanus toxin with ganglioside plays an essential part in the development of tetanus symptoms. However, it seemed possible that injection of ganglioside might affect the course of the disease. In the present work, experimental tetanus was induced in mice by injecting either purified toxin, or whole vegetative bacilli of Clostridium tetani. The effect of injecting ganglioside alone, or ganglioside complexed with cerebroside, at different times relative to the injection of toxin and by different routes, on the subsequent development of tetanus symptoms was examined. Hence it has been possible to investigate the prophylactic effect of such injections in experimentally induced tetanus in mice.

\section{METHODS}

Tetanus toxin was kindly provided by Dr R. O. Thomson (Wellcome Research Laboratories). Dilutions of toxin were made in $0^{\circ} \mathrm{I}$ M-phosphate ( $\mathrm{pH} 7 \cdot 0$ ) containing $0.2 \%$ gelatin (gelatin-buffer). Mixed gangliosides were prepared by the method described by Mellanby, Pope \& Ambache (1968). Cerebroside was prepared by the method of Klenk \& Leupold (1944). Ganglioside/cerebroside complexes were prepared as described by van Heyningen \& Mellanby (1968). Sialic acid was determined by the resorcinol + hydrochloric acid method of Svennerholm (1957).

Vol. 54, No. I, was issued 27 November 1968 
The strain of Clostridium tetani used was kindly provided by the Wellcome Research Laboratories. It was inoculated into sloppy agar Mueller medium (Mueller \& Miller, 1954). For the experiments, $250 \mathrm{ml}$. Mueller medium was inoculated with $0.5 \mathrm{ml}$. of an overnight culture in the sloppy agar, and incubated for $20 \mathrm{hr}$ at $37^{\circ}$. The organisms were collected by centrifugation at $9000 \mathrm{~g}$ for $15 \mathrm{~min}$., washed with $250 \mathrm{ml}$. $0.9 \% \mathrm{NaCl}$ and then resuspended in a suitable volume of $0.9 \% \mathrm{NaCl}$. Dilutions were made in $0.9 \% \mathrm{NaCl}$ and these were injected into mice.

Table I. Values assigned to symptoms of local tetanus induced in mice by injecting toxin intramuscularly into a hind limb

\begin{tabular}{lc}
\multicolumn{1}{c}{ Symptom } & $\begin{array}{r}\text { Value } \\
\text { assigned }\end{array}$ \\
$\begin{array}{l}\text { No symptoms } \\
\text { Slight stiffness in injected limb visible only } \\
\text { when mouse suspended by tail }\end{array}$ & 0 \\
An obvious limp in injected limb but it is still used & \\
effectively in walking & 2 \\
Injected limb still movable, but not functional & 3 \\
Injected limb rigid and even the toes immovable & 4 \\
Animal convulsing and generally very ill & 5 \\
Dead & 6
\end{tabular}

The symptoms of tetanus in mice were assessed on a numerical scale (Table 1 ). The symptoms in each group of mice under observation were assessed daily, for 7 days, after injection of tetanus toxin or vegetative bacilli of Clostridium tetani. In each group, the mean of the values assigned to the symptoms was calculated. In Fig. I the mean symptom (and the standard deviation of each point) in a group of 20 mice injected with 2 LD 50 of tetanus toxin is plotted against the time after injection. Figure I shows, incidentally, that the standard deviation in a group of injected mice was greater when the animals were near death. Death is affected by factors which do not influence the symptoms of intoxication-whether an animal dies at symptom 4 may depend on such extraneous factors as cannibalism (it was not feasible for us to use single-mouse cages). Therefore the intermediate effects are more meaningful than the final effects-which are the only ones observed in the customary determinations of either lethal dose or survival time.

\section{RESULTS}

Preliminary experiments indicated that the severity of tetanus symptoms in mice after injection with tetanus toxin was decreased when ganglioside had been injected some hours before the toxin. Table 2 shows the results of an experiment in which the effect of injecting ganglioside at different times and by different routes was tested on the subsequent development of tetanus symptoms (after injection of tetanus toxin). The experiment was done with 20 groups of ro mice. The four routes chosen for injection of ganglioside were: intramuscularly in the same leg which was subsequently injected with toxin; intramuscularly in the opposite hind leg; intravenously into the tail vein; intraperitoneally. Twenty-four hr before injection of toxin (2 LD 50) each of four groups of mice was injected with ganglioside by one of these four routes. Similarly, injections were done in three more sets of four groups of Io mice, with the ganglioside injected $6 \mathrm{hr}$ or $2 \mathrm{hr}$ before the toxin, or at the same time (that is, a few seconds 
afterwards). A further four groups of Io mice were injected with gelatin-buffer by one of each of the four routes, $2 \mathrm{hr}$ before injection of toxin. The mice were examined daily for 7 days after toxin injection and their tetanus symptoms assessed according to the scale in Table 1 . Table 2 shows that the mice which were given ganglioside at the same time as toxin, at the same site of injection, were protected against all but the mild symptoms of tetanus. Thus, while on the 7 th day after injection of toxin all the control mice (injected with toxin and gelatin-buffer) were dead, the gangliosideinjected mice showed only a limp (mean symptom $2 \cdot 6+0 \cdot 5$ ). Ganglioside given before the toxin at the same site as the toxin was less effective in protecting against tetanus the earlier it was given. When ganglioside was injected by other routes it was much

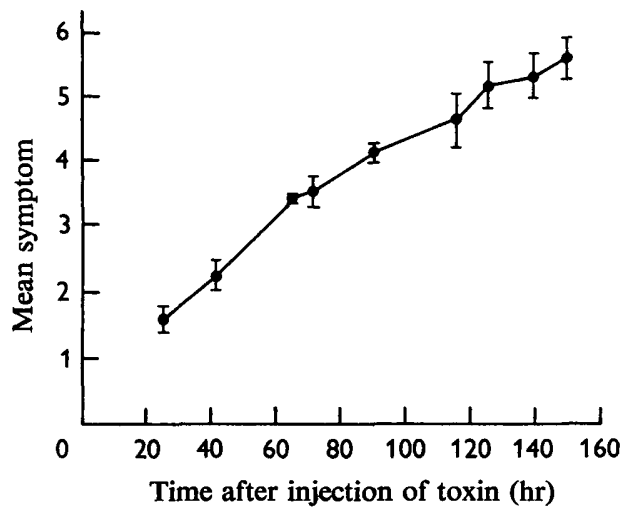

Fig. I

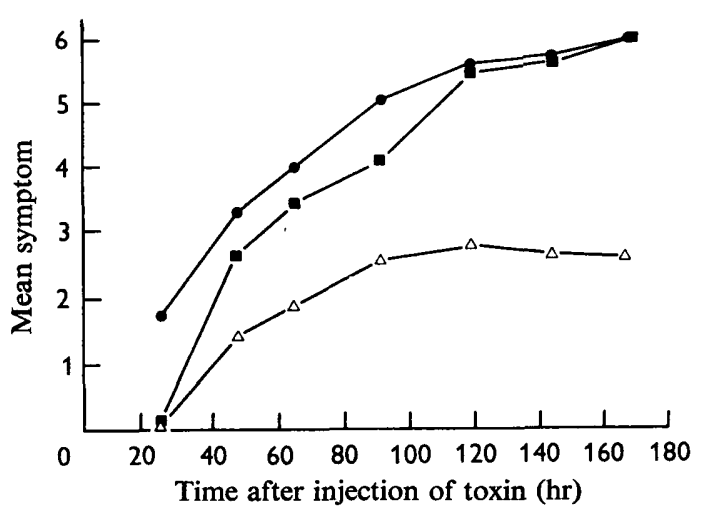

Fig. 2

Fig. I. The progression of tetanus symptoms in a group of 20 mice injected with 2 LD 50 tetanus toxin. (See Table I for assessment of symptoms. The vertical lines indicate the standard deviations of the values.)

Fig. 2. Protection of mice against 5 LD 50 of tetanus toxin with ganglioside/cerebroside complex ( $25 \%$ ganglioside). The values are the means of the symptoms in each group of 20 mice (see Table I). All the injections were intramuscular in the same hind limb. $\bullet$, Gelatinbuffer; $0,0.5 \mathrm{mg}$. ganglioside; $\triangle, 2 \mathrm{mg}$. ganglioside/cerebroside complex.

less effective, and the slight degree of protection it afforded was the same whether it was injected at the same time as the toxin or 2 or $6 \mathrm{hr}$ before. Ganglioside had no effect when injected (by any route) $24 \mathrm{hr}$ before the toxin. Intravenous injection of an amount of ganglioside which was only one quarter of that injected by the other routes had as much protective effect against tetanus toxin as the larger dose injected intraperitoneally or intramuscularly in the opposite leg. (This smaller dose was used for intravenous injection because the larger dose when injected intravenously was sometimes lethal to mice suffering from tetanus.)

The observation that the protective effect of the ganglioside was greatest when the ganglioside and toxin were injected at the same site in the animal, and at the same time, suggested that the protection might be due to fixation or inactivation (see van Heyningen, 196I) of the toxin by the ganglioside at the site of injection. It had previously been found that at low concentrations (a few LD 5o/ml.), tetanus toxin was fixed by complexes of ganglioside with cerebroside (Mellanby \& van Heyningen, 1965; van Heyningen \& Mellanby, 1968), the optimal proportion of ganglioside being about 
Table 2. The effect of injecting ganglioside at different times and by different routes on the subsequent development of symptoms after intramuscular injection of tetanus toxin

The figures are the means of the value ascribed to the tetanus symptom (sce Table $\mathrm{I}$ ) \pm the standard deviation in the group under consideration; the figures in parentheses denote the number of animals in the group.

Time (hr) before

toxin that ganglio-

side was injected

24

Gelatin-buffer injected $2 \mathrm{hr}$ before toxin

\section{Route of ganglioside injection}

Intraperitoneal

Intravenous

Intramuscular in same leg as toxin

Intramuscular in opposite leg to toxin

Intraperitoneal

Intravenous

Intramuscular in same leg as toxin

Intramuscular in opposite leg to toxin

\section{Intraperitoneal}

Intravenous

Intrasmuscular in same leg as toxin

Intramuscular in opposite leg to toxin

Intraperitoneal

Intravenous

Intramuscular in same leg as toxin

Intramuscular in opposite leg to toxin

Intraperitoneal

Intravenous

Intramuscular in same leg as toxin

Intramuscular in opposite leg to toxin
Day 3

$4 \cdot 0 \pm 0.67$ (10)

$4 \cdot 2 \pm 0.78$ (I0)

$3.5 \pm 0.53$ (I0)

$4 \cdot 2 \pm 0.42$ (10)

$3.5 \pm 0.56$ (9)

$3 \cdot 3 \pm 0.48$ (10)

$2.4 \pm 0.52$ (IO)

$3.3 \pm 0.48$ (IO)

$3 \cdot 6 \pm 0.49$ (I0)

$3.1 \pm 0.57$ (IO)

$\mathrm{I} \cdot 8 \pm 0.2 \mathrm{I}$ (10)

$3.5 \pm 0.53$ (10)

$40 \pm 0 \quad$ (I0)

$3.6 \pm 0.53$ (9)

$\mathrm{I} \cdot 7 \pm 0.48$ (I0)

$4.2 \pm 0.2$ I (IO)

4. I \pm 0.74 (I0)

$40 \pm 0 \quad$ (IO)

$4.0 \pm 0 \quad$ (I0)

$4.1 \pm 0.31(10)$
Day 5

$5 \cdot 5 \pm 0.72$ (10)

$5.3 \pm 0.48$ (10)

$4 \cdot 8 \pm 0.79$ (10)

$5.3 \pm 0.48$ (10)

$4 \cdot 3 \pm 1 \cdot 38$ (9)

$3.8 \pm 0.21$ (10)

$3.5 \pm 0.7 \mathrm{I}$ (10)

$4 \cdot 3 \pm 0.48$ (I0)

$4.3 \pm 0.45$ (10)

$3.9+0.78(10)$

$3 \cdot 0 \pm 0 \quad$ (10)

$4 \cdot 4 \pm 0.70$ (10)

$4.1 \pm 0.31$ (10)

$4.0 \pm 0.87$ (9)

$2 \cdot 3 \pm 0 \cdot 48$ (10)

$4.3 \pm 0.67$ (10)

$5 \cdot 2 \pm 0.84$ (IO)

$5.5 \pm 0.85$ (10)

$5 \cdot 0 \pm 0.81$ (I0)

$5.4 \pm 0.82$ (10)
Day 7

$6 \cdot 0 \pm 0 \quad$ (10)

$6.0 \pm 0 \quad$ (10)

$6 \cdot 0 \pm 0 \quad$ (10)

$6.0 \pm 0$ (I0)

$4 \cdot 9 \pm 1.05$ (9)

$4.4 \pm 0.89$ (10)

$45 \pm 1 \cdot 18$ (10)

$4.7 \pm 0.68$ (10)

$4 \cdot 7 \pm I \cdot 16$ (10)

$43 \pm 0.48$ (10)

$3.3 \pm 0.67$ (10)

$4 \cdot 6 \pm 0.85$ (10)

$4.8 \pm I .03$ (10)

$4.5 \pm 0.90$ (9)

$2.6 \pm 0.52$ (10)

$5 \cdot 3 \pm 0 \cdot 48$ (10)

$6 \cdot 0 \pm 0 \quad$ (I0)

$6 \cdot 0 \pm 0 \quad$ (10)

$6 \cdot 0 \pm 0 \quad$ (10)

$6 \cdot 0 \pm 0 \quad$ (I0) 
$25 \%$. If fixation of tetanus toxin by injected ganglioside were the reason for the protective effect of ganglioside, then it might be expected that a complex of ganglioside and cerebroside would also protect against tetanus toxin. Figure 2 illustrates the results of an experiment in which the protective effect of $0.5 \mathrm{mg}$. ganglioside alone was compared with the protection afforded by $0.5 \mathrm{mg}$. ganglioside complexed with $\mathrm{I} \cdot 5 \mathrm{mg}$. cerebroside. Three groups of 20 mice were used, and $5 \mathrm{hr}$ before the injection of 5 LD 50 of tetanus toxin: the first group was injected with $0.5 \mathrm{ml}$. gelatin-buffer only, the second group with $0.5 \mathrm{ml}$. gelatin-buffer containing $2 \mathrm{mg}$. ganglioside/ cerebroside complex ( $25 \%$ ganglioside) and the third group with $0.5 \mathrm{ml}$. gelatinbuffer containing $0.5 \mathrm{mg}$. ganglioside. The mean of the values ascribed to the symptoms

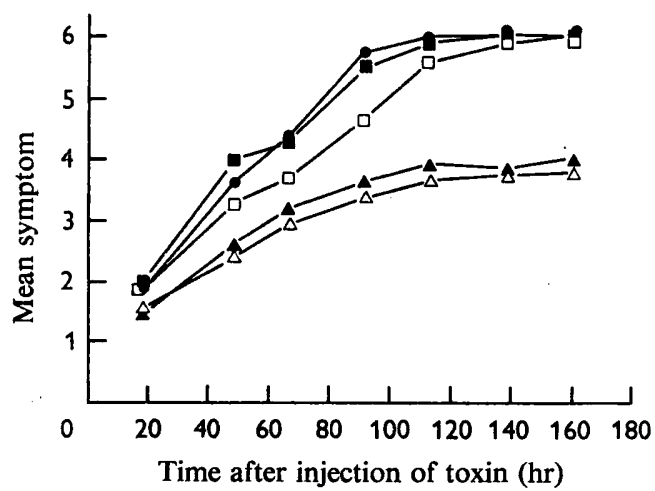

Fig. 3

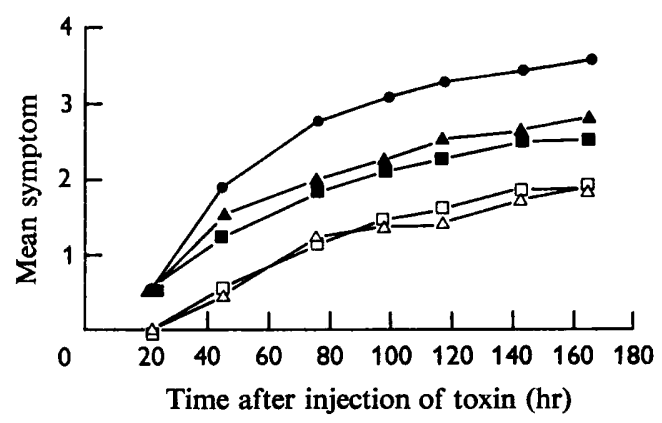

Fig. 4

Fig. 3. Protection of mice against $20 \mathrm{LD} 50$ of tetanus toxin with ganglioside/cerebroside complexes containing different proportions of ganglioside. The values are the means the symptoms in each group of 20 mice (see Table I). All the injections were intramuscular in the same hind limb. 9 , Gelatin-buffer; $\square$, cerebroside alone; $\square$, ganglioside/cerebroside ( $50 \%$ ganglioside); $\boldsymbol{\Delta}$, ganglioside/cerebroside ( $25 \%$ ganglioside); $\triangle$, ganglioside/cerebroside ( $5 \%$ ganglioside).

Fig. 4. A comparison of the protective effect of ganglioside and ganglioside/cerebroside complex injected $5 \mathrm{hr}$ before or $5 \mathrm{hr}$ after a challenge dose of $0.5 \mathrm{LD} 50$ tetanus toxin. The values are the means of the symptoms in each group of 20 mice (see Table I). All the injections were intramuscular in the same hind limb. 9 , Gelatin-buffer $5 \mathrm{hr}$ before or $5 \mathrm{hr}$ after; $\Delta, 2 \mathrm{mg}$. ganglioside/cerebroside complex $5 \mathrm{hr}$ after; $\boldsymbol{\square}, 5 \mathrm{mg}$. ganglioside $5 \mathrm{hr}$ after; $\triangle, 2 \mathrm{mg}$. ganglioside/cerebroside complex $5 \mathrm{hr}$ before; $\square, 5 \mathrm{mg}$. ganglioside $5 \mathrm{hr}$ before.

are plotted against the time after injection of the toxin. It can be seen that the ganglioside/cerebroside complex prevented the development of the severe symptoms of tetanus (the symptoms did not proceed beyond stage 3), whereas $0.5 \mathrm{mg}$. ganglioside had little effect on the progress of the symptoms. This observation was repeated in further experiments and it was also found that $5 \mathrm{mg}$. ganglioside alone was required to produce the same protection as $0.5 \mathrm{mg}$. of ganglioside in a ganglioside/cerebroside complex (see Fig. 4) and it was shown that cerebroside alone had no protective effect.

It had been shown previously that the complex of ganglioside and cerebroside containing $25 \%$ ganglioside was more effective (per unit weight of complex) in fixing tetanus toxin than a complex containing either 5 or $50 \%$ ganglioside. The effectiveness of these complexesin protecting against $5 \mathrm{LD} 50$ of tetanus toxin injected $5 \mathrm{hr}$ later was compared in the experiment illustrated in Fig. 3. In this experiment, equal amounts of ganglioside 
were injected in each case-thus with $50 \%$ ganglioside, I mg. complex was used; with $25 \%$ ganglioside, $2 \mathrm{mg}$. complex; and with $5 \%$ ganglioside, $10 \mathrm{mg}$. complex. It can be seen (Fig. 3) that the complex containing $50 \%$ ganglioside did not protect the mice against tetanus toxin, while the complexes containing 5 and $25 \%$ prevented death. Although these two complexes were equally effective in protection per unit weight of ganglioside, the complex containing $25 \%$ ganglioside was five times more effective per unit weight of complex. In a further experiment ganglioside/cerebroside complexes did not protect against tetanus toxin when the complex was injected intravenously instead of intramuscularly.

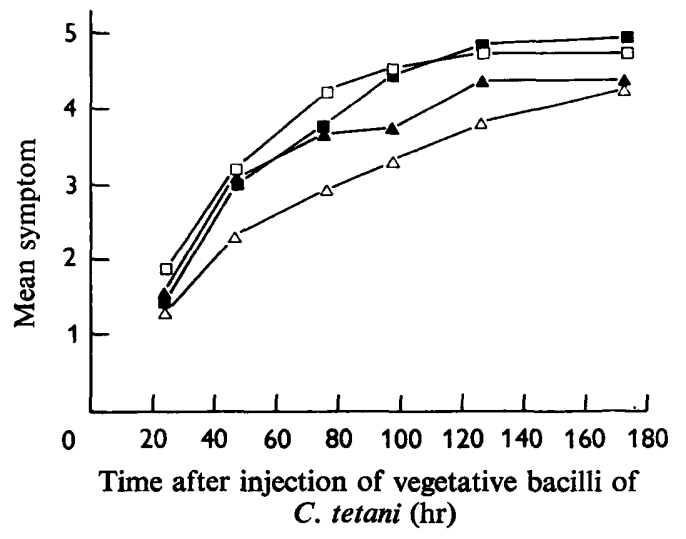

Fig. 5

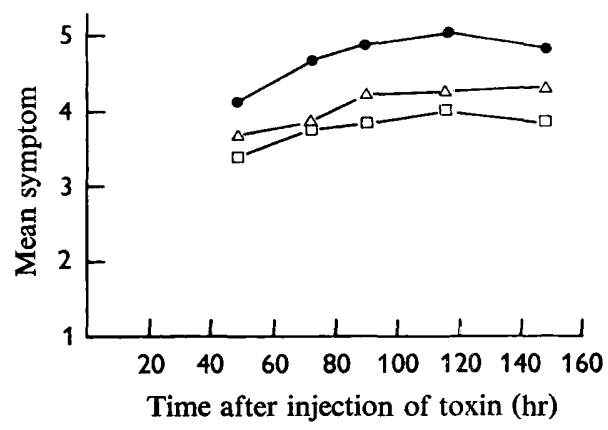

Fig. 6

Fig. 5. A comparison of the effectiveness of intramuscular and intravenous ganglioside in protecting mice against tetanus resulting from the injection of vegetative bacilli of Clostridium tetani $5 \mathrm{hr}$ before. The values are the means of the symptoms in each group of 20 mice (see Table I). The vegetative bacilli of C. tetani were injected intramuscularly in the hind limb and intramuscular ganglioside injections were made into the same limb. $\mathbf{a}$, Gelatin-buffer i.v.; $\square$, gelatin buffer i.m.; $\Delta, 5 \mathrm{mg}$. ganglioside i.v.; $\triangle, 5 \mathrm{mg}$. ganglioside i.m.

Fig. 6. A comparison of the effectiveness of ganglioside and ganglioside/cerebroside complex in protecting mice against tetanus resulting from the injection of vegetative bacilli of Clostridium tetani $5 \mathrm{hr}$ before. The values are the means of the symptoms in each group of 20 mice (see Table I). All the injections were intramuscular in the same hind limb. 9 , Gelatin-buffer; $\triangle, 2 \mathrm{mg}$. ganglioside/cerebroside complex; $\square, 5 \mathrm{mg}$. ganglioside.

These experiments showed that ganglioside and ganglioside/cerebroside complex were effective prophylactic agents against the development of tetanus symptoms resulting from the injection of purified tetanus toxin $5 \mathrm{hr}$ afterwards. If ganglioside were to be useful as a prophylactic agent in natural tetanus, it should be also be effective when introduced into the animal after the toxin. Figure 4 shows an experiment where a comparison was made of the protection afforded against $0.5 \mathrm{LD} 50$ of tetanus toxin by $5 \mathrm{mg}$. ganglioside or $2 \mathrm{mg}$. ganglioside/cerebroside (25\% ganglioside) complex injected either $5 \mathrm{hr}$ before or $5 \mathrm{hr}$ after the toxin. Both the ganglioside alone and the complex had more protective effect when injected before the toxin, but they still afforded protection when injected afterwards.

In considering natural tetanus it was also of interest to investigate whether ganglioside and ganglioside/cerebroside complex could protect mice against the development of symptoms resulting from the injection of live Clostridium tetani bacilli. The results 
of such an experiment are shown in Fig. 5. Vegetative bacilli (equivalent to I LD 50 as far as could be determined) were injected, and $5 \mathrm{hr}$ after this $5 \mathrm{mg}$. ganglioside was injected, either intramuscularly or intravenously. By either route this amount of ganglioside afforded some protection but, as in protection against the purified toxin, the intramuscular injection (same site of injection as the bacilli) was the more effective. Figure 6 shows the results of a comparable experiment where the protection by $2 \mathrm{mg}$. ganglioside/cerebroside complex, intramuscularly, was somewhat less than that by $5 \mathrm{mg}$. ganglioside (alone) by the same route.

\section{DISCUSSION}

The protective effect of ganglioside and of ganglioside/cerebroside complex against the effects of tetanus toxin injected intramuscularly was most marked when they were injected a few hours before, or at the same time, as the toxin, and at the same site. Also, $2 \mathrm{mg}$. of a complex containing $25 \%$ ganglioside was as effective as $10 \mathrm{mg}$. of a complex containing $5 \%$ ganglioside, and a complex containing $50 \%$ ganglioside was ineffective. It would therefore appear that the protection afforded by these complexes reflects their ability to fix tetanus toxin at low concentrations of toxin (van Heyningen \& Mellanby, 1968), although a complex containing $5 \%$ ganglioside is relatively more effective in protecting mice against tetanus toxin than in fixing tetanus toxin in vitro. When the ganglioside/cerebroside complex was injected intravenously it did not protect mice from tetanus. The complex is not water-soluble and the mixture which was injected was a thick suspension. It is probable that the particles in this suspension would be too large to escape from the circulation into the tissues and could not reach the site where their action would be needed.

Since ganglioside and ganglioside/cerebroside complex were also effective in protecting against tetanus induced by the injection of vegetative bacilli of Clostridium tetani, they might have some prophylactic value in human tetanus. It must, however, be stressed that the protective agent would have to be injected as near the site of injury as possible, and as soon as possible (when free toxin was injected the protective effect was no longer found when treatment was delayed for $24 \mathrm{hr}$ ). Di- and tri-sialogangliosides containing two sialic acid residues attached to each other have a much greater affinity for tetanus toxin than the other major gangliosides of nervous tissue (van Heyningen, 1963). It is likely that their prophylactic value would also be greater, but at present it is difficult to separate them in amounts large enough for this to be tested.

We thank Dr R. O. Thomson of the Wellcome Research Laboratories for providing the toxin and for help with the growth of the organism and $\mathrm{Mr} \mathrm{P}$. A. Thompson for drawing the figures. This work was done during tenure of a contract (Task no. 136-474) between W. E. van Heyningen and the Office of Naval Research of the United States Department of the Navy.

\section{REFERENCES}

KLENK, E. \& LEUPOLD, F. (1944). Über eine vereinfachte Methode zue Darstellung von phosphfreien cerebroside. Hoppe-Seyler's Z. physiol. Chem. 281, 208.

Mellanby, J. \& van Heyningen, W. E. (1965). The role of gangliosides in the mode of action of tetanus toxin. In Recent Advances in the Pharmacology of Toxin. Ed. by J. Raudonat. Oxford: Pergamon Press. 
Mellanby, J., Pope, D. \& Ambache, N. (1968). The effect of the treatment of crude tetanus toxin with ganglioside/cerebroside complex on sphincter paralysis in the rabbit's eye. J. gen. Microbiol. 50, 479.

MuelleR, J. H. \& Miller, P. A. (1954). Variable factors influencing the production of tetanus toxin. J. Bact. 67, 27 I.

SVENNERHOLm, L. (1957). Quantitative estimation of sialic acids. II. A colorimetric resorcinol-hydrochloric acid method. Biochim. biophys. Acta 24, 604.

VAN HEYNINGEN, W. E. (1959). Tentative identification of the tetanus toxin receptor in nervous tissue. J. gen. Microbiol. 20, 310.

VAN HeYNingen, W. E. (196I). The relation between the fixation and inactivation of tetanus toxin by ganglioside. Br. J. exp. Path. 42, 397.

Van Heyningen, W. E. (1963). The fixation of tetanus toxin, strychnine, serotonin and other substances by ganglioside. J. gen. Microbiol. 3I, 375 .

van Heyningen, W. E. \& Mellanby, J. (1968). The effect of cerebroside and other lipids on the fixation of tetanus toxin by gangliosides. J. gen. Microbiol. 52, 447.

van Heyningen, W. E. \& Miller, P. A. (I96I). The fixation of tetanus toxin by ganglioside. J. gen. Microbiol. 24, 107.

WassermanN, A. \& TAKAKI, T. (1898). Über tetanusantitoxische Eigenschaften des normalen Centralnervensystems. Berl. klin. Wschr. 35, 5. 